\title{
Effect of metformin on the survival of patients with ALL who express high levels of the $A B C B 1$ drug resistance gene
}

\author{
Christian Ramos-Peñafiel ${ }^{1}$, Irma Olarte-Carrillo², Rafael Cerón-Maldonado², Etta Rozen-Fuller ${ }^{1}$, \\ Juan Julio Kassack-Ipiña', Guillermo Meléndez-Mier ${ }^{3}$, Juan Collazo-Jaloma and Adolfo Martínez-Tovar ${ }^{1} 2^{*}$
}

\begin{abstract}
Background: In acute lymphoblastic leukemia (ALL), high ABCB1 gene expression has been associated with treatment resistance, which affects patient prognosis. Many preclinical reports and retrospective population studies have shown an anti-cancer effect of metformin. Therefore, the objective of this study was to assess the effect of metformin on the treatment regimen in patients with ALL who exhibited high levels of $A B C B 1$ gene expression and to determine its impact on overall survival.

Methods: A total of 102 patients with ALL were recruited; one group $(n=26)$ received metformin, and the other received chemotherapy $(n=76)$. Measurement of ABCB1 transcript expression was performed using qRT-PCR prior to treatment initiation. Survival analysis was performed using Kaplan-Meier curves. The impact of both the type of treatment and the level of expression on the response (remission or relapse) was analyzed by calculating the odds ratio.

Results: The survival of patients with high $A B C B 1$ expression was lower than those with low or absent ABCB1 gene expression $(p=0.030)$. In the individual analysis, we identified a benefit to adding metformin in the group of patients with high $A B C B 1$ gene expression $(p=0.025)$. In the metformin user group, the drug acted as a protective factor against both therapeutic failure (odds ratio [OR] 0.07, 95\% confidence interval [CI] 0.0037-1.53) and early relapse (OR $0.05,95 \% \mathrm{Cl} 0.0028-1.153)$.
\end{abstract}

Conclusion: The combined use of metformin with chemotherapy is effective in patients with elevated levels of ABCB1 gene expression. Trial registration NCT 03118128: NCT

Keywords: ATP binding cassette subfamily B member 1 (ABCB1), Quantitative real-time polymerase chain reaction (qRT-PCR), Acute lymphoblastic leukemia (ALL)

\section{Background}

Acute lymphoblastic leukemia (ALL) is the most frequent malignancy in children and adolescents $[1,2]$ and is characterized by lack of control in the normal mechanisms of proliferation, differentiation and apoptosis inhibition. Despite the great diversity of treatments, cure remains unfavorable in adult patients: the cure rate is almost $90 \%$ in children but is unfortunately approximately $30-40 \%$

\footnotetext{
*Correspondence: mtadolfo73@hotmail.com

${ }^{2}$ Laboratorio de Biología Molecular, Servicio de Hematología, Hospital General de México, "Dr. Eduardo Liceaga", Ciudad de México, México Full list of author information is available at the end of the article
}

in adults $[3,4]$. Therefore, new treatment strategies that are less toxic, accessible and that improve cure rates are needed $[5,6]$. The mechanisms of tumor failure in the overexpression of drug transporters involved in the expulsion of drugs, such as daunorubicin, doxorubicin, etoposide, vincristine or vinblastine, and mitoxantrone, prevent the drug's mechanism of action and limit its activity [7-12] Among the most studied transporters is the $\mathrm{ABCB} 1$ gene, which encodes a $170-\mathrm{kDa}$ protein called P-glycoprotein (Pgp-170) [13-15] Our group previously reported that $52 \%$ of patients with ALL overexpressed the ABCB1 gene, which was associated with lower survival [16]. Metformin (1,1-dimethylbiguanide 
hydrochloride) has been shown to have anti-proliferative, anti-invasive, and anti-metastatic effects in multiple cancer cells $[17,18]$. At the molecular level, metformin activates metabolic stress via the AMPK pathway, resulting in the inhibition of several metabolic pathways, such as the mitochondrial respiratory chain and the signaling pathway mediated by nuclear factor kappa B (NFKB) [19-21] This effect could be beneficial in patients with ALL since it has been demonstrated that NF-KB is responsible for activating the overexpression of $\mathrm{ABCB} 1$ genes [22-25] The use of metformin in the pre-induction stage combined with steroids may enhance chemosensitivity and promote the survival of patients with ALL.

Preclinical studies have shown that the use of metformin combined with chemotherapeutics such as doxorubicin, paclitaxel and carboplatin have antiproliferative effects in a mouse xenograft model of breast cancer [26]. Additionally, low doses of metformin inhibit the cellular transformation of four genetically different types of breast cancer. The combination of metformin and doxorubicin reduces the tumor mass and prevents relapse [27].
Thus, the objective of the present study was to evaluate the efficacy of metformin in a cohort of patients diagnosed with Philadelphia-negative immunophenotype B ALL at the pre-induction stage expressing different levels of multi-resistance gene (ABCB1) and its treatment response as well as overall patient survival. We demonstrated the protective effect of metformin in the pre-induction stage in patients with high $\mathrm{ABCB} 1$ gene expression levels, who exhibited prolonged overall survival and a reduced risk of refractoriness and relapse compared to the control group.

\section{Methods}

Study design

This was a prospective clinical study with adult ALL patients diagnosed according to the Franco-American-British classification and confirmed by flow cytometry. The assignment of the groups was through simple randomization (3:1). After informed consent was obtained, 102 patients were included in the study; 26 patients received metformin (metformin users) in the

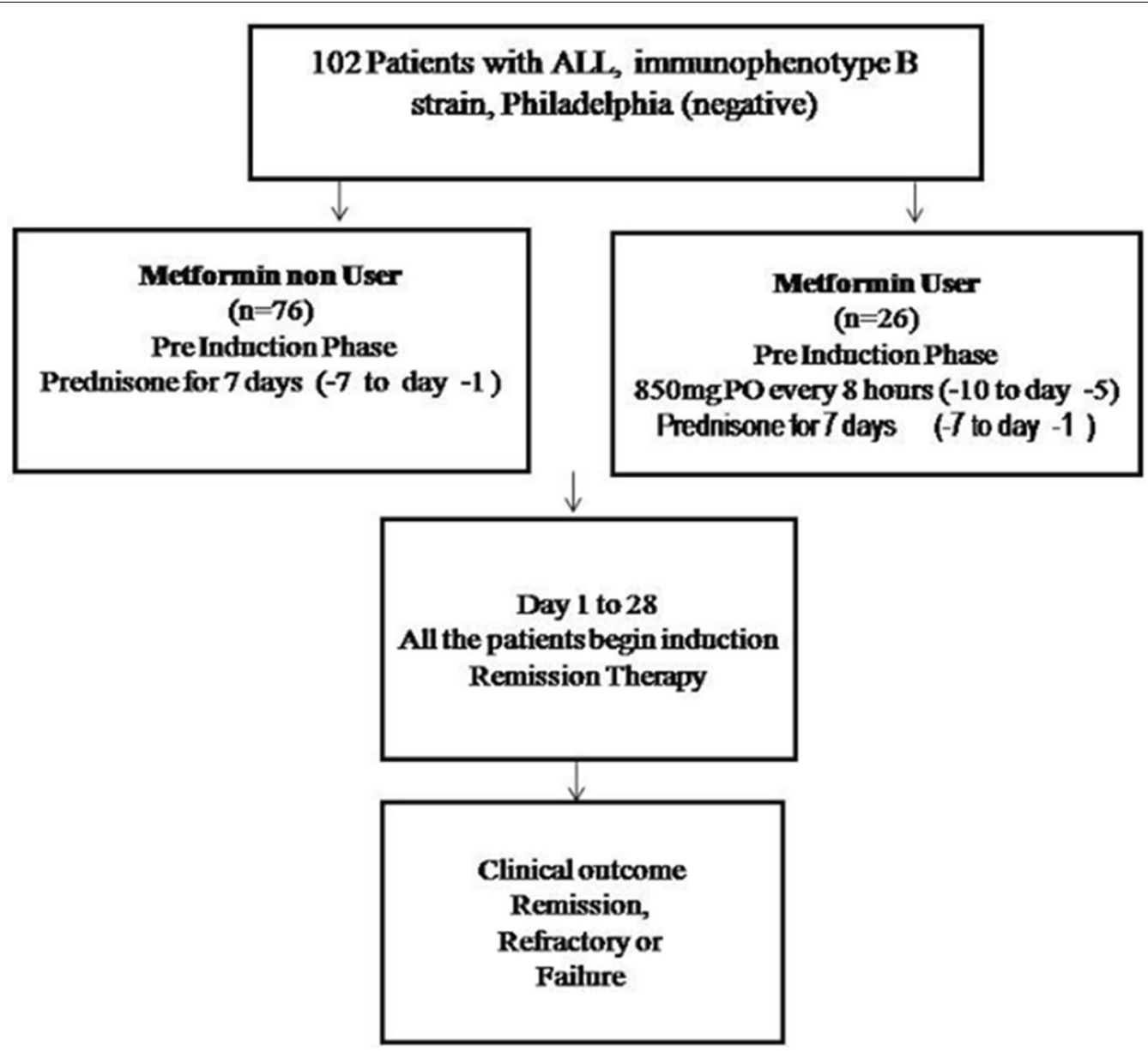

Fig. 1 Treatment scheme used in the two ALL patient treatment groups 
pre-induction stage at $850 \mathrm{mg}$ PO every $8 \mathrm{~h}$ in conjunction with the chemotherapy regimen LALHGM07, and 76 patients received chemotherapy (metformin nonusers) exclusively (Fig. 1).

All patients had a leukemia B phenotype, and patients with diabetes were excluded, as were cases carrying the Philadelphia chromosome or a cytogenetic alteration with poor prognosis. Expression levels of the ABCB1 gene were measured prior to initiation of treatment. This clinical trial was approved by the Ethics, Research and Biosafety Committees of the General Hospital of Mexico "Dr. Eduardo Liceaga" D1/15/103/03/57. The study adhered to the principles of the recent revision to the Declaration of Helsinki. All participants provided signed forms indicating prior consent.

\section{Analysis of $A B C B 1$ expression}

Expression levels of the ABCB1 gene were evaluated prior to treatment initiation in both treatment groups. All samples were collected from the bone marrow, and the mononuclear cells were separated using Ficoll-Hypaque Hypaque (Lymphoprep, Nycomed Pharma AS, density $1.077 \mathrm{~g} / \mathrm{L}$ ). The mononuclear cell phase was separated and suspended in PBS medium and stored at $-70{ }^{\circ} \mathrm{C}$. RNA Isolation was performed using TRIzol ${ }^{\circledR}$ (Invitrogen/ Life Technologies). The RNA was stored at $-80{ }^{\circ} \mathrm{C}$ until needed.

For cDNA synthesis, $2 \mu \mathrm{g}$ of RNA, final volume of $20 \mu \mathrm{L}$ was combined with $200 \mathrm{U}$ of the MMLV RT enzyme (Invitrogen, Carlsbad, CA, USA).

\section{Real-time polymerase chain reaction (qRT-PCR) analysis} The mRNA expression levels of the ABCB1 (Hs01069047) and glyceraldehyde 3-phosphate dehydrogenase (GAPDH; Hs00985689) genes were measured using TaqMan gene expression assays [16] (Applied Biosystems Foster City, CA, USA). The GAPDH gene was used as an endogenous control, and each sample was analyzed in triplicate.

The relative expression levels were calculated using the $2^{-\Delta \Delta \mathrm{Ct}}$ method. The high and low expression cutoff points were determined based on the mean values observed in 99 healthy donors [16].

\section{Response to treatment}

The treatment was checked at day 28 based on bone marrow uptake.

Complete Remission was defined as the patient having less than $5 \%$ of blasts at the end of induction therapy, Refractory patients remained leukemic, and Therapeutic Failure was defined as the patient dying
Table 1 Frequency of ABCB1 gene expression in patients metformin non user and metformin user

\begin{tabular}{|c|c|c|}
\hline & $\begin{array}{l}\text { Metformin non- } \\
\text { user, } n=76 \text { ( } 75 \%)\end{array}$ & $\begin{array}{l}\text { Metformin } \\
\text { user, } n=26 \\
(25 \%)\end{array}$ \\
\hline Age (median) & $35(18-78)$ & $31(18-61)$ \\
\hline \multicolumn{3}{|l|}{ Gender } \\
\hline Male & $36(47.4)$ & $13(50)$ \\
\hline Female & $40(52.6)$ & $13(50)$ \\
\hline Leukocytes (median) $\left(10^{3} / \mathrm{mcl}\right)$ & $45.1(0.4-251)$ & $42.1(1.2-220)$ \\
\hline \multicolumn{3}{|l|}{ Type of risk } \\
\hline Standard risk & $33(43.4)$ & $18(69.2)$ \\
\hline High risk & $43(56.6)$ & $08(30.8)$ \\
\hline \multicolumn{3}{|l|}{ Expression ABCB1 (\%) } \\
\hline Absence expression & $28(36.8)$ & $8(30.8)$ \\
\hline Low expression & $14(18.4)$ & $6(23.1)$ \\
\hline High expression & $34(44.7)$ & $12(46.2)$ \\
\hline \multicolumn{3}{|l|}{ Expression combination (\%) } \\
\hline Low and missing expression & $42(55.3)$ & $14(53.8)$ \\
\hline High expression & $34(44.7)$ & $12(46.2)$ \\
\hline \multicolumn{3}{|l|}{ Treatment failure } \\
\hline Remission complete & $47(61.8)$ & $18(69.2)$ \\
\hline Death or refractoriness & $29(38.2)$ & $08(30.8)$ \\
\hline
\end{tabular}

during therapy. Patients who had complete remission and who presented an increase in the number of blasts $(>5 \%)$ at any time were considered to be in Relapse. The consolidation phase consisted of the administration of sequential blocks of chemotherapy, including administration of high doses of methotrexate. At the end of the study, the patients started the maintenance phase by administering weekly mercaptopurine and methotrexate for a duration of 2 years. In case of relapse to bone marrow, the patients received rescue therapy.

\section{Statistical analysis}

Data were collected in MS Excel (Microsoft Corporation, Redmond WA, USA) and were analyzed in SPSS statistical software (version 20 for Windows: IBM, Armonk, NY, USA). A survival analysis was performed using KaplanMeier curves. The difference between the two groups was determined using the log-rank test $(\mathrm{p}=0.05)$. Both the type of treatment and the level of expression on response (remission or relapse) were analyzed by calculating the odds ratios.

\section{Results}

A total of 102 patients with B-immunophenotype-free were enrolled and divided into two groups: metformin users $(\mathrm{n}=26)$ and metformin non-users $(\mathrm{n}=76)$. 
The mean age for the metformin user group was 31 years (range of 18-61 years), and 13 women and 13 men were included, with a median leucocyte count of $42.1 \times 10^{3} / \mathrm{mcl}$ (range of $1.2-220 \times 10^{3} / \mathrm{mcl}$ ). Regarding the metformin non-user group, the mean age was 35 years (range 18-78 years). The patients were both female $(n=40,52.6 \%)$ and male $(n=36,47.4 \%)$, with a measured leukocyte count $45.1 \times 10^{3} / \mathrm{mcl}$ (range 0.4$251 \times 10^{3} / \mathrm{mcl}$ ) (Table 1$)$.

When analyzing the relative ABCB1 gene expression levels prior to treatment initiation in the 102 patients, $45.1 \%$ (46/102) had high expression levels, $19.6 \%$ (20/102) had low levels, and only $35.2 \%$ (36/102) did not express the gene. The proportions of patients with high expression were similar in the two treatment groups $46.2 \%$ $(12 / 26)$ in the metformin user group and $44.7 \%(34 / 76)$ in the metformin non-user group), as were the low and negative expression levels (Table 1).

The effect of expression levels of the ABCB1 gene on overall survival (OS) at 60 months demonstrated that high levels of ABCB1 gene expression were associated with a lower OS of $41.5 \%(19 / 46)$ in ALL patients; low and negative expression had OS values of $70 \%(14 / 20)$ and $69.5 \%$ (25/36), respectively. The results indicated a significant decrease in patients with high levels of ABCB1 gene expression, similar to our previously reported findings ( $\mathrm{p} \leq$, log-rank test) (Fig. 2).

However, when evaluating the two treatment groups (metformin users and metformin non-users), there were no significant differences between the groups $(\mathrm{p}=0.251$, 95\% confidence interval [CI]) (Fig. 3), confirming that no therapeutic benefit was evident in the OS in 102 patients, without considering ABCB1 gene expression levels. Therefore, we analyzed only those patients who reported high levels of ABCB1 gene expression (46/102) and its effect on OS. In these patients, increased survival was observed in the metformin user group $(83.3 \%$, $10 / 12)$ compared with the metformin non-user group $26.6 \%$, (9/34), decreasing the risk of therapeutic failure $(\mathrm{p}=0.025,95 \% \mathrm{CI})$ (Fig. 4). No significant changes were observed in OSB patients with low or negative levels of ABCB1 gene expression (Figs. 5, 6).

When assessing the type of risk in the treatment groups, in terms of refractoriness, $\mathrm{ABCB} 1$ gene expression demonstrated an increased risk of drug failure (odds ratio [OR] 7.48, 95\% CI 0.36-153.79) with other clinical

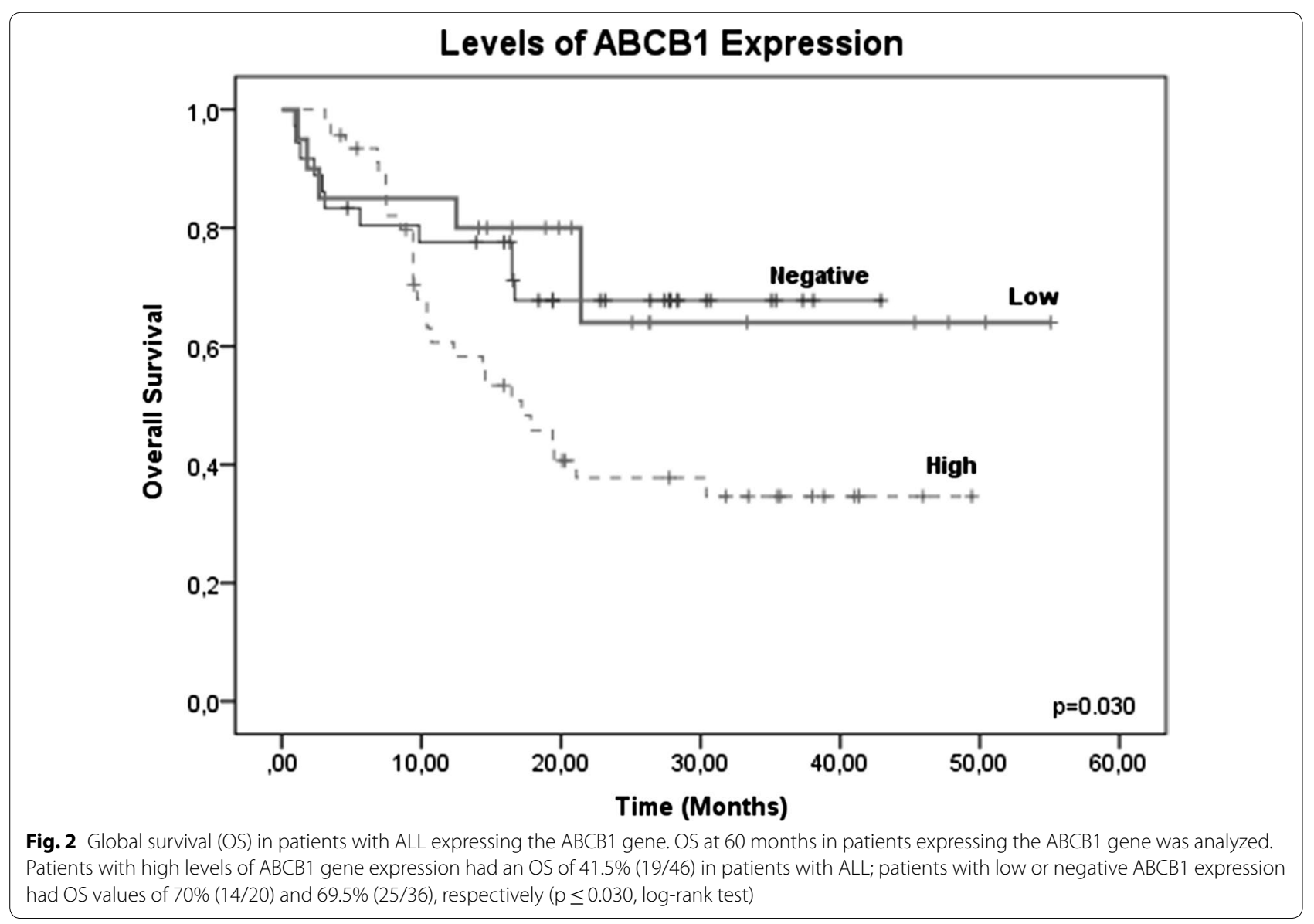


variables, such as age over 35 years (OR 2.25, 95\% CI $0.30-16.63$ ) and white blood cell count (OR 6.00, 95\% CI 0.56-63.98). Regarding relapse, high levels of ABCB1 gene expression were also associated with an increased risk of relapse (OR 2.91, 95\% CI 0.28-30.29) compared with clinical variables such as age greater than 35 years (OR 3.42, 95\% CI 0.49-23.77) and leukocyte count (OR 8.57, 95\% CI 0.82-89.04). In the metformin user group, metformin could function as a protective factor against both therapeutic failure and early relapse (OR 0.07, 95\% CI $0.003-1.53$ and OR 0.05 , 95\% CI $0.0028-1.15$ ) (Table 2).

\section{Discussion}

Although most of the clinical evidence was obtained from the observational, studies or patients with advanced stages of treatment, it can be concluded that metformin is beneficial for the prevention of the appearance of new cancers and as an adjuvant to different treatment modalities [26-29]. These results indicate that the capacity of metformin to be combined with different treatment strategies is very broad; its application is more relevant for tumors that express AMPK/mTOR activity [30]. It can also be applied with drugs involved in cellular metabolism or in the synthesis, where effectiveness is improved with new strategies such as immunotherapy [25]. Recently, the use of metformin has been combined with tyrosine kinase inhibitors (imatinib, sorafenib), and it has been effective in improving responses in cases of not only chronic myeloid leukemia but also myeloid leukemia with mutations in FLT3/ITD $[28,29]$. Regarding the association between high ABCB1 gene expression and the activation of energy-dependent P (gp170) glycoprotein (ATP), energy depletion is an attractive strategy to overcome resistance to different drugs, including cytotoxic drugs (daunorubicin, doxorubicin, etoposide, vincristine or vinblastine, and mitoxantrone) or even antibiotics [10, 31-34]. To date, there have been few trials to explain the effects of metformin on the expression of drug resistance genes. Recently, in a cell model of hepatocarcinoma cells (HepG2, HepG2/ADM, LO2), Wu et al. reported that the addition of metformin $(1 \mu \mathrm{mol} / \mathrm{L}$ for $24 \mathrm{~h}$ and subsequently for $48 \mathrm{~h}$ at $1.5 \mu \mathrm{mol} / \mathrm{L}$ ) decreased gp170 expression by blocking the expression of nuclear factor NF-kB,

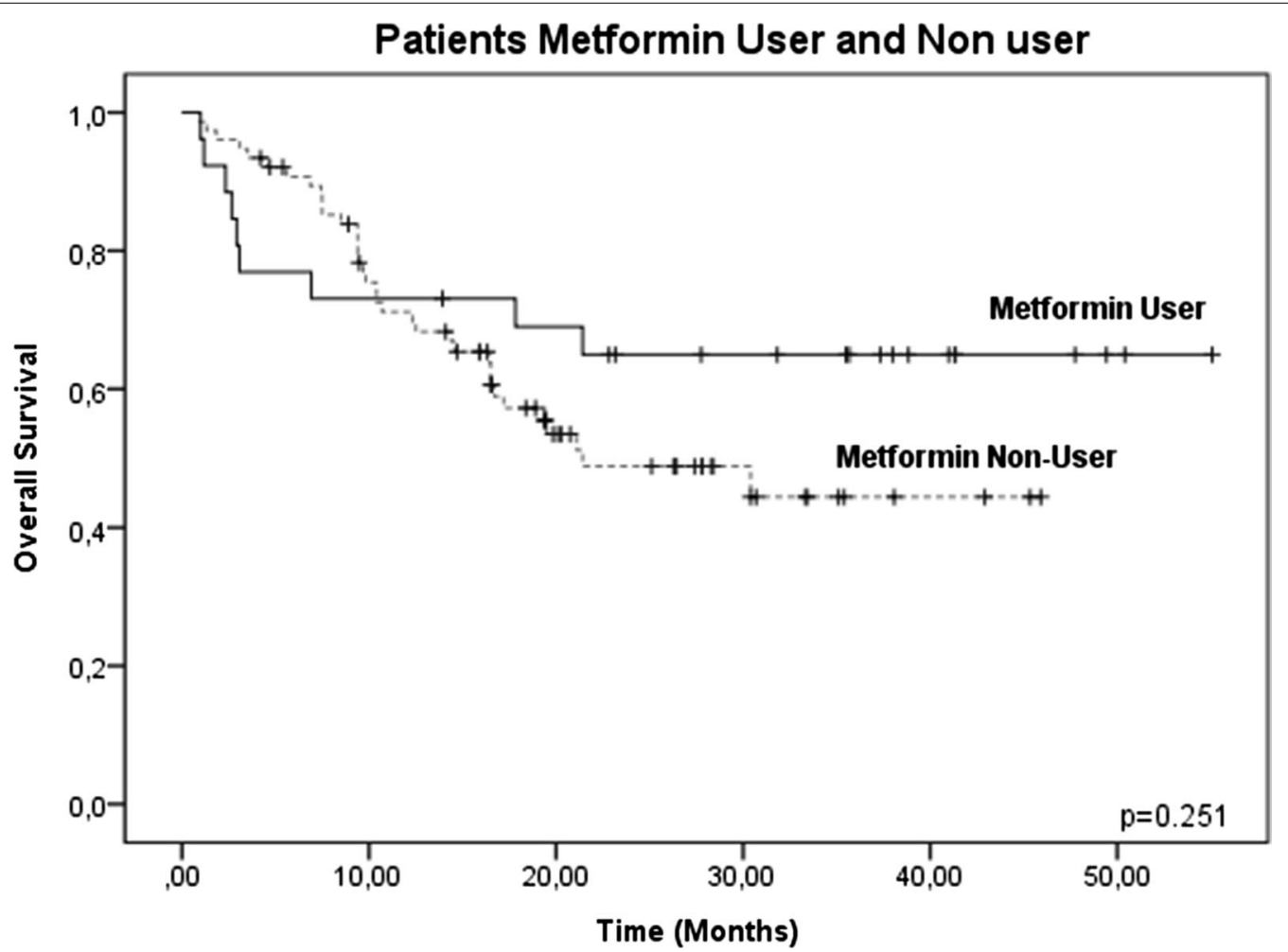

Fig. 3 Global survival (OS) in patients with ALL treated with metformin (metformin users and metformin non-users). OS at 60 months in patients treated with metformin was analyzed, and no significant differences were found between the two groups $(p=0.251,95 \% \mathrm{Cl})$ 
inducing hepatocyte apoptosis. Similar to the model of Kim and collaborators in the doxorubicin-resistant MCF-7/Dox cell line, Xue and colleagues were also able to demonstrate the effects of metformin on the decrease in drug resistance in association with 2-deoxyglucose by decreased glucose uptake and ATP depletion by increasing the toxic effect of doxorubicin by compromising the function of the p53 tumor suppressor gene $[35,36]$. These results are greatly relevant, since metformin, which is an expensive and accessible drug with a tolerable safety profile (rare cases of lactic acidosis), may ameliorate one of the main therapeutic failure mechanisms in cancer [37, 38]. Although there is strong evidence from in vitro trials, perhaps the major criticism of the use of metformin is that most of the evidence is obtained from observational trials [39-41], and evaluating its effects in a few randomized placebo trials have failed to identify a beneficial effect of treatment [42-46].

In our study, the pretreatment baseline $\mathrm{ABCB} 1$ gene expression was defined, which allowed for an independent stratification of clinical risk. According to the previous results, patients with high levels of $\mathrm{ABCB} 1$ gene expression have an adverse prognosis [16]. However, when metformin was added to the pre-induction stage for this group of patients, its beneficial effect manifested as improved clinical outcomes and a reduced number of therapeutic failures. This finding was similar to the findings of some observational studies or case reports in which the effect of metformin on the treatment of tumors in advanced or metastatic cases was considered beneficial [47-51].

\section{Conclusion}

Although clinical evidence in leukemia patients is scarce, we consider that its use in this stage of treatment is beneficial only in patients with high levels of $\mathrm{ABCB} 1$ gene expression. Therefore, a greater number of studies in this specific subgroup of patients should be performed to determine whether that benefit could be extended for the detection of minimal residual disease or in patients after transplantation of hematopoietic progenitor cells.

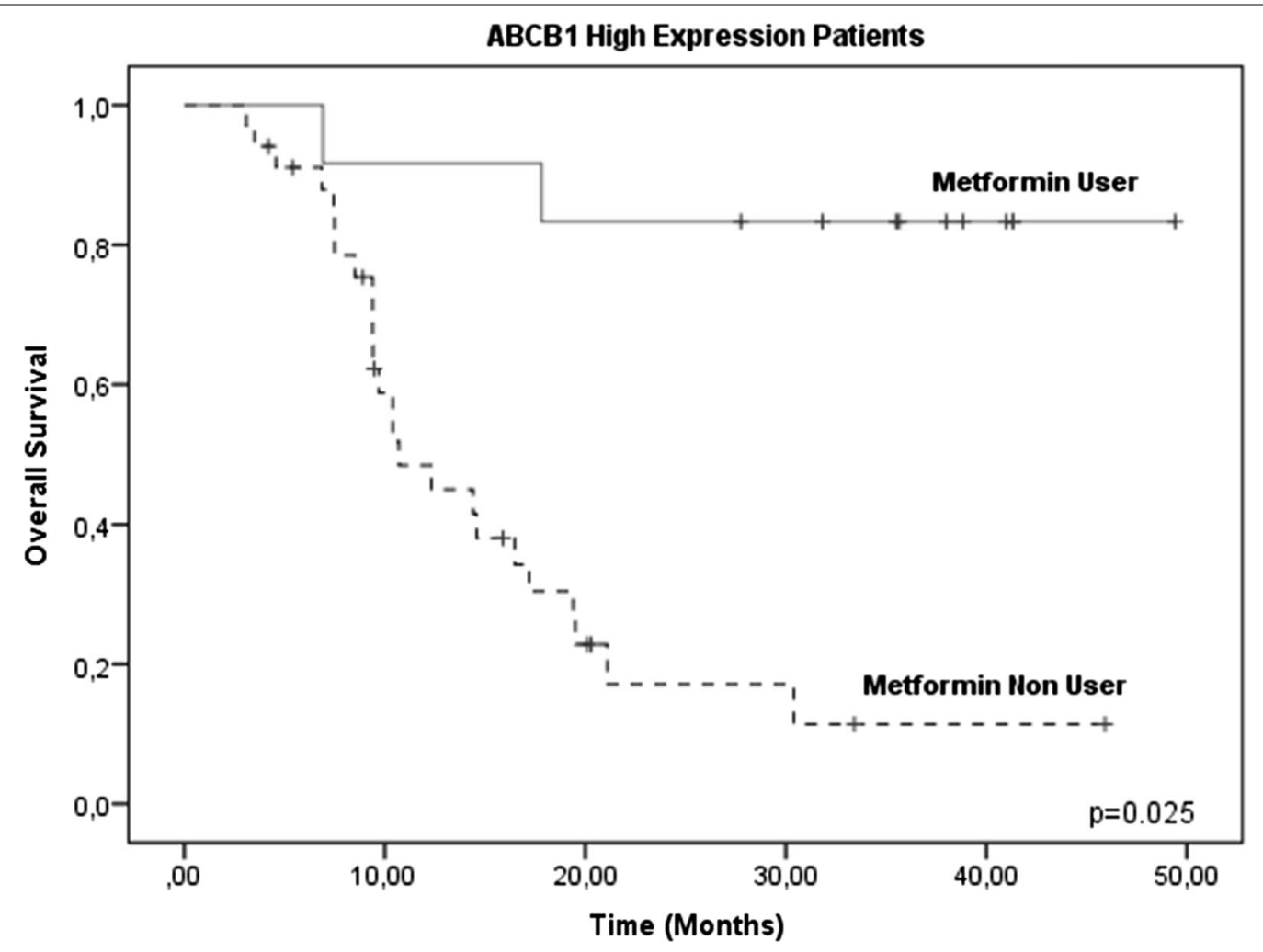

Fig. 4 Global survival (OS) in patients with metformin-treated ALL (metformin users) and ALL without metformin treatment (metformin non-users) with elevated levels of $A B C B 1$ gene expression. OS at 60 months in Metformin-treated patients and high levels of ABCB1 expression was analyzed, and metformin had a protective survival benefit $(p=0.025,95 \% \mathrm{Cl})$ 


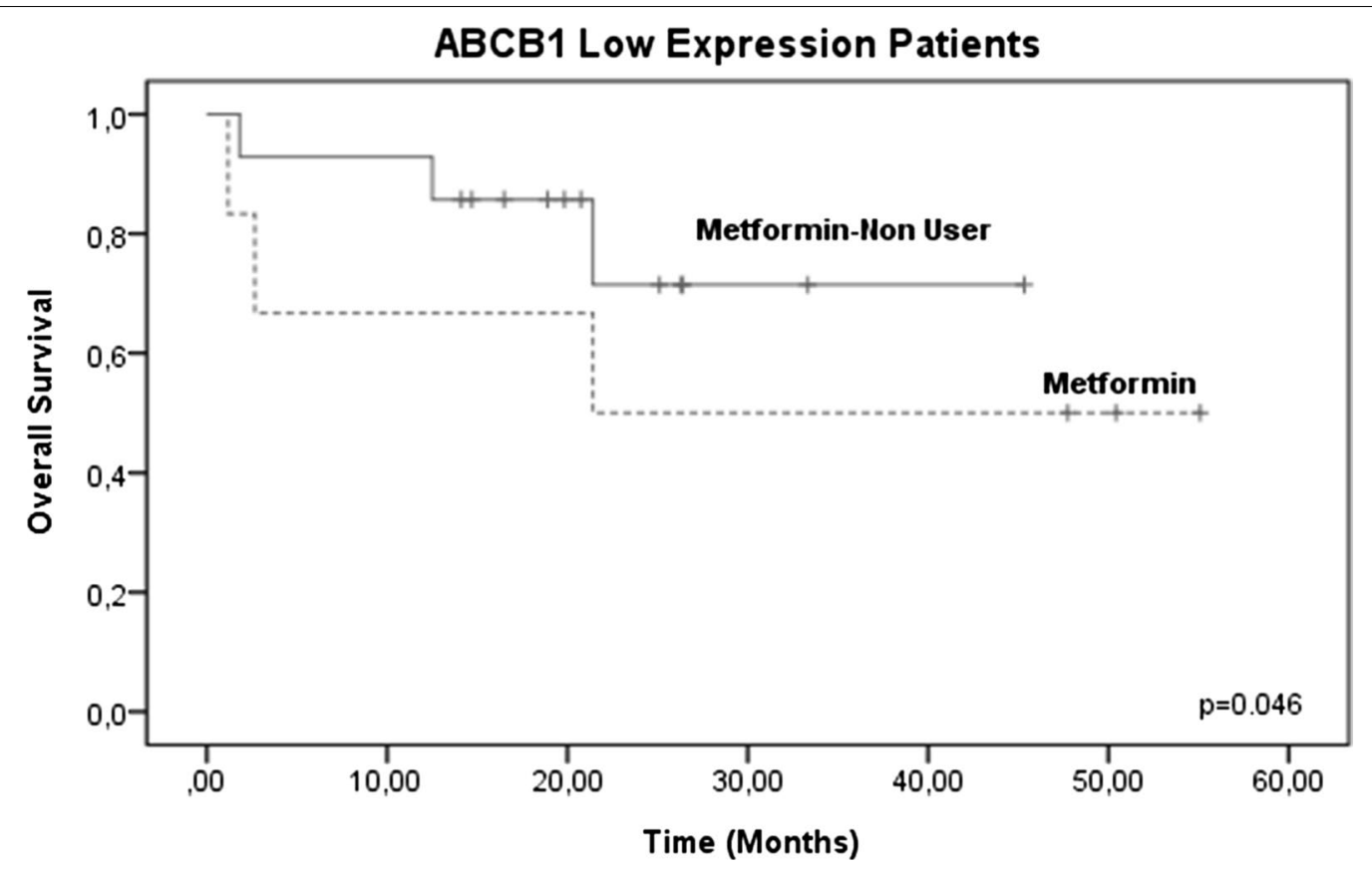

Fig. 5 Global survival (OS) in patients with metformin-treated ALL (metformin users) and ALL without metformin treatment (metformin non-users) with low $A B C B 1$ gene expression levels. No significant changes were observed in OS in the patients with low ABCB1 gene expression levels $(p=0.046,95 \% \mathrm{Cl})$

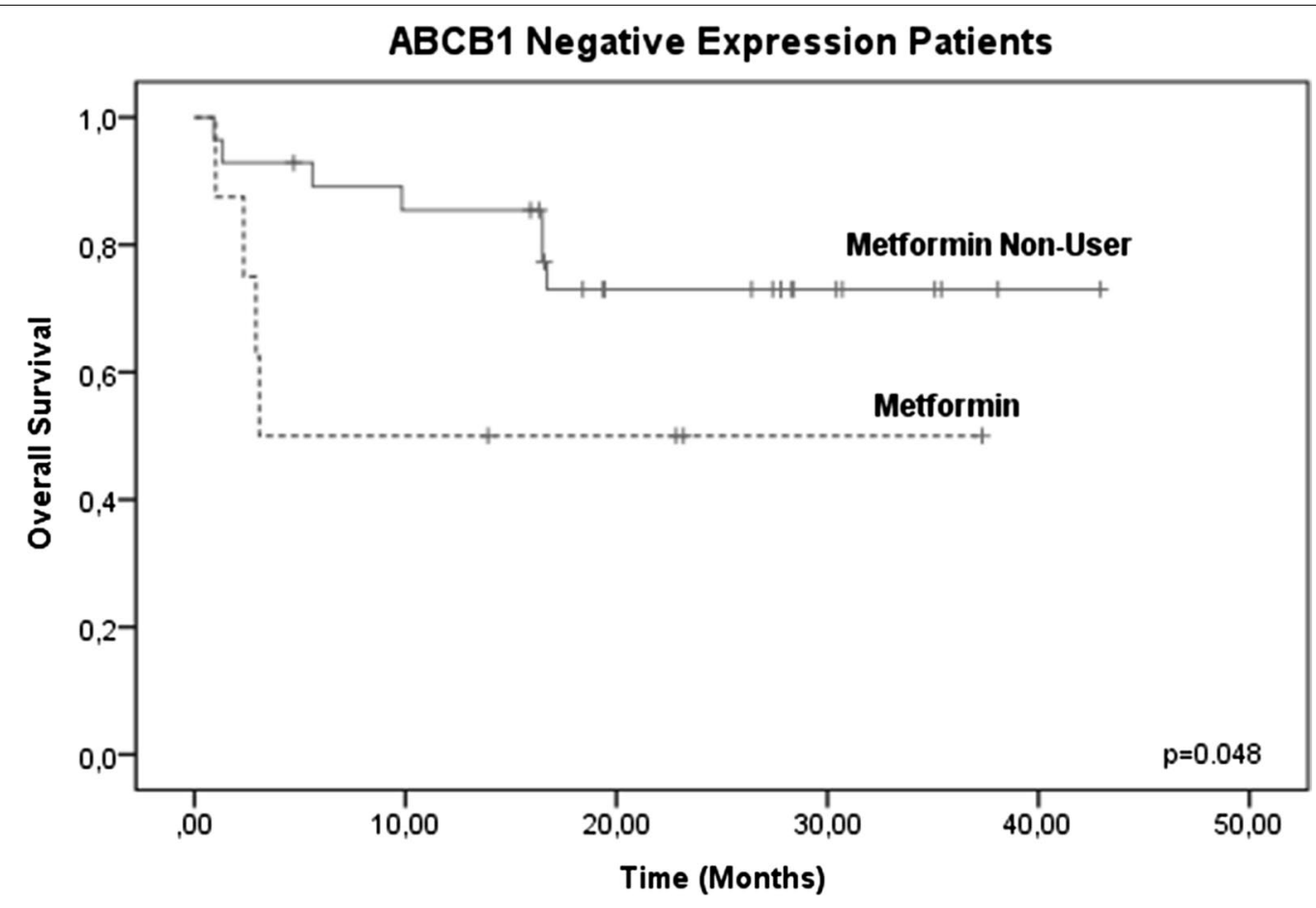

Fig. 6 Global survival (OS) in patients with metformin-treated ALL (metformin users) and ALL without metformin treatment (metformin non-users) with negative $A B C B 1$ gene expression levels. No significant changes were observed in OS in the patients with low $A B C B 1$ gene expression levels $(p=0.048,95 \% \mathrm{Cl})$ 
Table 2 ALL patients mortality and OR model according to use of metformin

\begin{tabular}{|c|c|c|c|c|c|c|}
\hline & \multicolumn{3}{|c|}{ Refractoriness } & \multicolumn{3}{|c|}{ Relapse } \\
\hline & OR & $(95 \% \mathrm{Cl})$ & $\mathbf{p}$ & OR & $(95 \% \mathrm{Cl})$ & $\mathbf{p}$ \\
\hline Age $>35$ years & 2.25 & $0.30-16.63$ & 0.426 & 3.42 & $0.49-23.77$ & 0.214 \\
\hline Leukocytes $>30 \times 10^{3} / \mathrm{mcl}$ & 6.00 & $0.56-63.98$ & 0.137 & 8.57 & $0.82-89.04$ & 0.072 \\
\hline Metformin user & 0.07 & $0-1.5$ & 0.091 & 0.05 & $0-1.15$ & 0.061 \\
\hline Expression $\mathrm{ABCB} 1$ negative or high & 7.48 & $0.36-153.79$ & 0.192 & 2.91 & $0.28-30.29$ & 0.896 \\
\hline
\end{tabular}

OR odds ratio, $C l$ confidence interval, $A B C B 1$ ATP binding cassette subfamily $B$ member 1

\section{Abbreviations}

$\mathrm{Ph}^{+} \mathrm{ALL}$ : Philadelphia chromosome-positive acute lymphoblastic leukemia; qRT-PCR: real-time quantitative polymerase chain reaction; $B C R-A B L$ : breakpoint cluster region, Abelson; TKIs: tyrosine kinase inhibitors; BM: bone marrow; B-ALL: B cell acute lymphoblastic leukemia; WHO: World Health Organization; BMMNCs: bone marrow mononuclear cells; MoAbs: monoclonal antibodies; Ara-C: cytarabine arabinoside; dNTP: deoxy-ribonucleotide triphosphate; CR: complete remission; RFS: relapse-free survival; OS: overall survival; FAB: French-Britain-American; WBC: white blood cell; OR: odds ratio; HR: hazard ratio; $\mathrm{Cl}$ : confidence interval.

\section{Authors' contributions}

CHRP made main contributions to the document, designed the research, and participated in specimen collection, sorting data, data analysis and drafting the manuscript; IOC, RCM, ERF and JJKI assisted in specimen collection and the acquisition of clinical data; GMM and JCJ were mainly responsible for follow-up; and AMT provided substantial guidance and revised the manuscript. All authors read and approved the final manuscript.

\section{Author details}

1 Servicio de Hematología, Hospital General de México, "Dr. Eduardo Liceaga", Ciudad de México, México. ${ }^{2}$ Laboratorio de Biología Molecular, Servicio de Hematología, Hospital General de México, "Dr. Eduardo Liceaga”, Ciudad de México, México. ${ }^{3}$ Dirección de Investigación, Hospital General de México, "Dr. Eduardo Liceaga", Ciudad de México, México.

\section{Acknowledgements}

Christian Ramos Peñafiel thanks the "Posgrado en Ciencias Médicas y Odontológicas, UNAM". No. 99607537. American Journal Experts (http://www. journalexperts.com) provided editorial assistance to the authors during the preparation of the manuscript.

We thank the patients and their relatives who contributed to this study.

\section{Competing interests}

The authors declare that they have no competing interests.

\section{Availability of date and materials}

The datasets supporting the conclusions of this article are included within the article.

\section{Consent for publication}

Not applicable.

\section{Ethics approval and consent to participate}

This study was approved by the Ethics Committee of the General Hospital of Mexico (Registration Numbers: HGM/DI/08/204/04/17, D1/15/103/03/57) and registered at Clinical Trials.gov (number NCT031181). Clinical and informed consent was obtained from each patient or their family members.

\section{Funding}

This project was supported by HGM (HGM/DI/08/204/04/17,

D1/15/103/03/57)

\section{Publisher's Note}

Springer Nature remains neutral with regard to jurisdictional claims in published maps and institutional affiliations.

Received: 3 July 2018 Accepted: 25 August 2018

Published online: 03 September 2018

\section{References}

1. Ferlay J, Soerjomataram I, Dikshit R, et al. Cancer incidence and mortality worldwide; sources, methods and major patterns in GLOBOCAN 2012. Int J Cancer. 2015;136(5):359-86.

2. Bray F, Piñeros M. Cancer patterns, trend and projections in Latin America and the caribbean: a global context. Salud Publica Mex. 2016;58(2):104-17.

3. Urruticoechea A, Alemany R, Balart J, Villanueva A, Viñals F, Capellá G. Recent advances in cancer therapy: an overview. Curr Pharm Des. 2010;16(1):3-10.

4. Wong $\mathrm{AH}$, Deng CX. Precision medicine for personalized cancer therapy. Int J Biol Sci. 2015:11(12):1410-2.

5. Howard DH, Chernew ME, Abdelgawad T, Smith GL, Sollano J, Grabowski DC. New anticancer drugs associated with large increases in costs and life expectancy. Health Aff (Millwood). 2016;35(9):1581-7.

6. Mariotto AB, Yabroff KR, Shao Y, Feuer EJ, Brown ML. Projections of the cost of cancer care in the United States: 2010-2020. J Natl Cancer Inst. 2011;103(2):117-28

7. Linton KJ. Structure and function of $A B C$ transporters. Physiology. 2007;22:122-30.

8. El-Awady R, Saleh E, Hashim A, et al. The role of eukaryotic and prokaryotic abc transporter family in failure of chemotherapy. Front Pharmacol. 2017:10(7):535.

9. Joshi AA, Vaidya SS, St-Pierre MV, et al. Placental ABC transporters: biological impact and pharmaceutical significance. Pharm Res. 2016;33(12):2847-78

10. Chen Z, Shi T, Zhang L, et al. Mammalian drug efflux transporters of the ATP binding cassette $(A B C)$ family in multidrug resistance: a review of the past decade. Cancer Lett. 2016;370(1):153-64.

11. Wijdeven RH, Pang B, Assaraf YG, Neefjes J. Old drugs, novel ways out: drug resistance toward cytotoxic chemotherapeutics. Drug Resist Updat. 2016:28:65-81.

12. Fletcher JL, Williams RT, Henderson MJ, Norris MD, Haber M. ABC transporters as mediators of drug resistance and contributors to cancer cell biology. Drug Resist Update. 2016;26:1-9.

13. Fukuda Y, Lian S, Schuetz JD. Leukemia and ABC transporters. Adv Cancer Res. 2015;125:171-96.

14. Jonge-Peeters SD, Kuipers F, deVries EG, Vellenga E. ABC transporter expression in hematopoietic stem cells and the role in $\mathrm{AML}$ drug resistance. Crit Rev Oncol Hematol. 2007;62(3):214-26.

15. Shaffer BC, Gillet JP, Patel C, Baer MR, Bates SE, Gottesman MM. Drug resistance: still a daunting challenge to the successful treatment of AML. Drug Resist Updat. 2012;15(1-2):62-9.

16. Olarte Carrillo I, Ramos Peñafiel C, Miranda Peralta E, et al. Clinical significance of the $A B C B 1$ and $A B C G 2$ gene expression levels in acute lymphoblastic leukemia. Hematology. 2017;14:1-6. 
17. Leclerc GM, Leclerc GJ, Kuznetsov JN, De Salvo J, Barredo JC. Metformin induces apoptosis through AMPK-dependent inhibition of UPR signaling in ALL lymphoblasts. PLOS ONE. 2013;8:e74420.

18. Martinez VL, Smith S, Toban N, Bazile M, Aloyz R. Resistance to Dasatinib in primary chronic lymphocytic leukemia lymphocytes involves AMPKmediated energetic re-programming. Oncotarget. 2013;4:2550-66.

19. Kim HG, Hien TT, Han EH, Hwang YP, Choi JH, Kang KW. Metformin inhibits P-glycoprotein expression via the NF-k B pathway and CRE transcriptional activity through AMPK activation. Br J Pharmacol. 2011:162(5):1096-108.

20. Owen MR, Doran E, Halestrap AP. Evidence that metformin exerts its antidiabetic effects through inhibition of complex 1 of the mitochondrial respiratory chain. Biochem J. 2000;348:607-14.

21. Scotland S, Saland E, Skuli N, de Toni F. Mitochondrial energetic and AKT status mediate metabolic effects and apoptosis of metformin in human leukemic cells. Leukemia. 2013;27:2129-38.

22. Cohen R, Neuzillet C, Tijeras-Raballand A, Faivre S, de Gramont A, Raymond E. Targeting cancer cell metabolism in pancreatic adenocarcinoma. Oncotarget. 2015;6:16832-47.

23. Evans JM, Donnelly LA, Emslie-Smith AM, Alessi DR, Morris AD. Metformin and reduced risk of cancer in diabetic patients. BMJ. 2005;330(7503):1304-5.

24. Lei Y, Yi Y, Liu Y, Liu X, Keller ET, Qian CN, Zhang J, Lu Y. Metformin targets multiple signaling pathways in cancer. Chin J Cancer. 2017;36(1):17.

25. Zhang HH, Guo XL. Combinational strategies of metformin and chemotherapy in cancers. Cancer Chemother Pharmacol. 2016;78(1):13-26.

26. Iliopoulos D, Hirsch HA, Struhl K. Metformin decreases the dose of chemotherapy for prolonging tumor remission in mouse xenografts involving multiple cancer cell types. Cancer Res. 2011;71(9):3196-201.

27. Hirsch HA, Iliopoulos D, Tsichlis PN, Struhl K. Metformin selectively targets cancer stem cells, and acts together with chemotherapy to block tumor growth and prolong remission. Cancer Res. 2009;69(19):7507-11.

28. Peng M, Darko KO, Tao T, et al. Combination of metformin with chemotherapeutic drugs via different molecular mechanisms. Cancer Treat Rev. 2017;54:24-33.

29. Scharping NE, Menk AV, Whetstone RD, Zeng X, Delgoffe GM. Efficacy of PD-1 blockade is potentiated by metformin-induced reduction of tumor hypoxia. Cancer Immunol Res. 2017;5(1):9-16.

30. Gadducci A, Biglia N, Tana R, Cosio S, Gallo M. Metformin use and gynecological cancers: a novel treatment option emerging from drug repositioning. Crit Rev Oncol Hematol. 2016:105:73-83.

31. Shi R, Lin J, Gong Y, et al. The antileukemia effect of metforminin the Philadelphia chromosome-positive leukemia cell line and patient primary leukemia cell. Anticancer Drugs. 2015;26(9):913-92.

32. Wang F, Liu Z, Zeng J, et al. Metformin synergistically sensitizes FLT3-ITDpositive acute myeloid leukemia to sorafenib by promoting mTOR-mediated apoptosis and autophagy. Leuk Res. 2015;39(12):1421-7.

33. Locher KP. Mechanistic diversity in ATP-binding cassette (ABC) transporters. Nat Structu Mol Biol. 2016;23(6):487-93.

34. Choi YH, Yu AM. ABC transporters in multidrug resistance and pharmacokinetics, and strategies for drug development. Curr Pharm Des. 2014:20(5):793-807.
35. Rohiff C, Glazer R, et al. Regulation of the MDR1 remote by cyclic AMPdependent protein kinase and transcription factor SP1. Int J Oncol. 1998;12(2):383-6.

36. Parissenti AM, Gannon BR, Villeneuve DJ, et al. Lack modulation of MDR-1 gene expression by dominant inhibition of CAMP-dependent protein kinase doxorubicin-resistance MCF-7 breast cancer cells. Int J Cancer. 1999:82(86):893-900.

37. Wu W, Yang JL, Wang YL, et al. Reversal of multidrug resistance of hepatocellular carcinoma cells by metformin through inhibiting NF-kB gene transcription. World J Hepatol. 2016;8(23):985-93.

38. XueC WangC, Sun Y, et al. Targeting P-glycoprotein function, p53 and energy metabolism: combination of metformin and 2-deoxyglucose reverses the multidrug resistance of MCF-7/Dox cells to doxorubicin. Oncotarget. 2017;8(5):8622-32.

39. Havesy MR. Metformin-associated lactic acidosis: an atypical presentation. Adv Emerg Nurs J. 2017;39(1):26-30.

40. Almirall J, Bricullé M, Gonzalez-Clemente JM. Metformin-associated lactic acidosis in type 2 diabetes mellitus: incidence and presentation in common clinical practice. Nephrol Dial Transplant. 2008;23(7):2436-8.

41. Dowling RJ, Niraula S, Stambolic V, Goodwin PJ. Metformin in cancer: translational challenger. J Mol Endocrinol. 2012;48(3):R31-43.

42. Benoit V, Guigas B, Sanz N, et al. Cellular and molecular mechanism of metformin: an overview. Clin Sci. 2012;122(6):253-70.

43. Golozar A, Liu S, Lin JA, Peairs K, Yeh HC. Does metformin reduce cancer risks? Methodologic considerations. Curr Diab Rep. 2016;16(1):4

44. Zhang XW, Ma YX, Sun Y, et al. Gemcitabine in combination with a second cytotoxic agent in the first-line treatment of locally advanced or metastatic pancreatic cancer: a systematic review and meta-analysis. Target Oncol. 2017;12(3):309-21.

45. Kordes S, Pollak MN, Zwinderman AH, Mathôt RA, Weterman MJ, Beeker A, Punt CJ, Richel DJ, Wilmink JW. Metforminin patients with advanced pancreatic cancer: a double-blind, randomized, placebo-controlled phase 2 trial. Lancet Oncol. 2015;16(7):839-47.

46. Ahmed I, Ferro A, Cohler A, et al. Impact of metformin use on survival in locally-advanced, inoperable non-small cell lung cancer treated with definitive chemoradiation. J Thorac Dis. 2015;7(3):346-55.

47. Montaudié H, Cerezo M, Bahadoran P. Metforminmono therapy in melanoma: a pilot, open-label, prospective and multicentric study indicates no benefit. Pigment Cell Melanoma Res. 2017;30(3):378-80.

48. Khawaja MR, Nick AM, Madhusudanannair V, et al. Phase I dose escalation study of temsirolimus in combination with metformin in patients with advanced/refractory cancers. Cancer Chemother Pharmacol. 2016;77(5):973-7.

49. Ezewuiro $\mathrm{O}$, Grushko TA, Kocherginsky M, et al. Association of metformin use with outcomes in advanced endometrial cancer treated with chemotherapy. PLoS One. 2016;11(1):e0147145.

50. Kaddis N, Saif MW. Second-line treatment for pancreatic cancer. JOP. 2014;15(4):344-7.

51. Tan $B X, Y a o W X, G e J$, et al. Prognostic influence of metformin as first-line chemotherapy for advanced non small cell lung cancer in patients with type 2 diabetes. Cancer. 2011;117(22):5103-11.

Ready to submit your research? Choose BMC and benefit from

- fast, convenient online submission

- thorough peer review by experienced researchers in your field

- rapid publication on acceptance

- support for research data, including large and complex data types

- gold Open Access which fosters wider collaboration and increased citations

- maximum visibility for your research: over 100M website views per year

At BMC, research is always in progress.

Learn more biomedcentral.com/submissions 